\title{
Sea Level Variations of Zhejiang Province, China
}

\author{
Pingbo Wang1, Liuzhu Wang², Mantravadi Venkata Subrahmanyam²* \\ ${ }^{1}$ Daishan Natural Resources and Planning Bureau, Zhoushan, China \\ ${ }^{2}$ School of Marine Science and Technology, Zhejiang Ocean University, Zhoushan, China \\ Email: ^mvsm.au@gmail.com
}

How to cite this paper: Wang, P.B., Wang, L.Z. and Subrahmanyam, M.V. (2020) Sea Level Variations of Zhejiang Province, China. Open Access Library Journal, 7: e6409. https://doi.org/10.4236/oalib.1106409

Received: May 9, 2020

Accepted: May 24, 2020

Published: May 27, 2020

Copyright (c) 2020 by author(s) and Open Access Library Inc.

This work is licensed under the Creative Commons Attribution International License (CC BY 4.0).

http://creativecommons.org/licenses/by/4.0/

\section{(c) (i) Open Access}

\begin{abstract}
In this paper we consider the Zhejiang (ZJ) provincial coastal area to find the sea level (SL) variations. Sea Surface Height Relative to Geoid over these areas has been obtained from the satellite altimetry data produced routinely by the European Centre for Medium-Range Weather Forecasting (ECMWF) and Archiving, Validation and Interpretation of Satellite Oceanographic (AVISO) data. Monthly, seasonal and interannual variations of SL over ZJ have been presented and discussed. SL is indicating an increasing trend; however, there is a decreasing trend between the years 1975 and 1987. Over ZJ increase in SL increase is $0.34 \mathrm{~mm}$ in SL from 1958 to 1975 and after 1987 there is $0.24 \mathrm{~mm}$ increase, overall increase is $0.17 \mathrm{~mm}$ from 1958 to 2015; however, decrease in SL $0.26 \mathrm{~mm}$ from 1975 to 1987. Maximum SL observed in 2012. Negative relation between SL and Sea surface temperature (SST) found over ZJ province.
\end{abstract}

\section{Subject Areas \\ Geomorphology, Natural Geography}

\section{Keywords}

Sea Level, Zhejiang, Satellite Altimetry Data, SST

\section{Introduction}

Sea level (SL) variation is one of the important parameters of the earth's response to climate change [1]. Raise in SL receiving more and more attentions of global researchers as one of the catastrophic consequences of climate change. Modern SL rise is a matter of urgent concern from a variety of points of view, but especially because of the possibility of its acceleration and consequent threats 
to many low-lying parts of the world [2] [3] [4]. Since 1980, Global sea level rise rate has an increasing trend. Meanwhile, the rising rate of China's coastal sea level is higher than that of the world [5] [6]. Since 2000, Except for a slight decline in 2005, China's coastal sea level continued to be increasing and 2012 reached its highest level since 1980 [7]. From 2010 to 2012 China's coastal sea level in 2 - 3 a, 8 - 9 a and quasi 19a high periodical oscillation, several high superimposed periodical oscillations had obvious effect on the sea level. In 2012, coastal temperature and SST were higher $0.4^{\circ} \mathrm{C}$ and $0.3^{\circ} \mathrm{C}$ respectively than the usual years [8]. The anomaly of the wind leads to water accumulation is one of the causes of rising sea levels. In 2012, it was the tropical cyclones landing time and had wide influence, especially in August 2012 has six tropical cyclones affect China's coastal and had made obvious affect on sea level rise in that month. Subtropical high in 2012, north by east and the characteristics of the weak in the east China sea and south China sea have some influence of rising sea levels [8]. In the context of global warming, sea level rise has become a major global environmental problem, the impact of rising sea level on the economic development of coastal areas, marine ecological environment and people's production and life is increasingly significant.

The change of offshore sea level is related to the human living environment and its development prospect, so it gets more attentions. In recent decades, many experts have made a lot of investigations to get consistent understanding: In recent 100 years, the global sea level is on the rise and the average rise rate is about $1.0-2.0 \mathrm{~mm} / \mathrm{a}$ according to previous studies [9]-[16]. Average annual variability of the sea level along the coast of China is in the same range however, there are significant differences in sea level at different regions.

Mean global SL and mean global sea surface temperature (SST) has strong correlation [17] which suggests that the steric effect impact sea level signature. In addition to global warming factors, in the long-time scale, sea level changes are affected by structural changes in the earth, the activities of the great glacial period, and the effects of the atmosphere, the ocean itself, and other factors. Numerous studies have shown that the change of sea level is closely related to the water thermal expansion [8] [18] [19] [20] [21] [22]. Further this is supported by the strong similarity of the spatial distribution of satellite-observed in sea level variations and surface temperature [23] [24] [25]. By the year 2100, rises in temperatures are predicted by $2^{\circ} \mathrm{C}-4.4^{\circ} \mathrm{C}$ leading to global average sea level rise of 2 - $6 \mathrm{~mm}$ per year up to 2100 [26] with impacts for protected coastal habitats. Local sea surface temperature variations of about $0.58^{\circ} \mathrm{C} \cdot \mathrm{yr}^{-1}$ are observed and would be adequate to account for sea level rise.

\section{Study Area and Data}

Zhejiang is a province with the most islands in China, among which Zhoushan Archipelago is the largest. Zhejiang coastline extending 6486 kilometers and a total ocean area of 220,000 square kilometers. In addition, the province has a 
large number of bays with over 60 natural ports of different sizes, constituting a port-cluster among which Ningbo Port, Wenzhou Port and Zhoushan Port are the most important. Under subtropical and monsoon conditions, Zhejiang has four distinct seasons. It has an average annual temperature of $15^{\circ} \mathrm{C}-18^{\circ} \mathrm{C}, 230$ 270 frost-free days and an average annual rainfall of $1000-1900 \mathrm{~mm}$. It has numerous rivers with a mean annual surface water runoff of over 90 billion cubic meters. Zhejiang is located in the southern part of the Yangtze River Delta on the southeast coast of China, which accounts for sediment transport to sea. The Study area we chosen $26-32^{\circ} \mathrm{N}: 119-124^{\circ} \mathrm{E}$ to find out the variations of SL over Zhejiang Province.

Sea Surface Height Relative to Geoid over the area has been obtained from the operational ORAS4 data used for this analysis. The European Centre for Medium-Range Weather Forecasting (ECMWF) estimates the state of the global ocean via the operational system Ocean-S4. Ocean-S4 gives an estimate of the history of the ocean from September 1957 to present (with a few days delay) via the Ocean Reanalysis System 4 (ORAS4), as well as the latest ocean conditions, provided by the real-time extension Ocean Real Time Analysis System 4 (ORTA4). In this study, the data over the period of January 1958 to December 2015 monthly data are used to show sea level variations of the study area. And a merged and gridded Delayed Time Updated (DTUpd) product of Maps of Sea Level Anomalies (MSLA) is used in the study. The DT-Upd MSLA products are produced by AVISO based on TOPEX/Poseidon, Jason1, Jason 2, Envisat and ERS-1, 2 data (see SSALTO/DUACS User Handbook). This product has been corrected by usual geophysical errors such as solid earth, ocean and pole tides, wet and dry troposphere, ionosphere and inverted barometric effects. The monthly sea level anomaly data on a $1 / 3^{\circ} \times 1 / 3^{\circ}$ Mercater grid are obtained from AVISO website [27]. The altimeter data over the period of January 1993 to December 2012 are used to compute the regional average and the spatial distribution of the sea level rising rate.

To validate the relation between the SL and sea surface temperature (SST) relation we have used the dataset HadISST (Hadley Centre Global Sea Ice and Sea Surface Temperature) is a combination of monthly globally complete fields of SST and sea ice concentration for 1871-present. HadISST uses reduced space optimal interpolation applied to SSTs from the Marine Data Bank (mainly ship tracks) and ICOADS through 1981 and a blend of in-situ and adjusted satellite-derived SSTs for 1982-onwards. The "bucket correction" was applied to SSTs for 1871-1941. SSTs in boxes partially covered by sea ice were estimated from statistical relationships between SSTs and sea ice concentrations. SSTs were assigned a fixed value $\left(-1.8^{\circ} \mathrm{C}\right)$ for areas with sea ice cover of greater than $90 \%$. HadISST is primarily intended to be used as boundary conditions for atmospheric models. Version 1.1 is the current version. Using the above-mentioned data, SL variations are computed and presented in the following sections also given the relation between SL and SST. 


\section{Results}

\subsection{Monthly Variations of Sea Level over Zhejiang Province}

To understand the SL variations over Zhejiang area, we have averaged the SL over the study area and the variations are presented in Figure 1. It is clearly observed that SL is showing an increasing trend over Zhejiang province. SL is varying between $0.046 \mathrm{~m}$ and $0.48 \mathrm{~m}$. Lower SL monthly variations can be observed in 1961-62, 1967-68. Higher SL monthly variations can be observed in 1975, 2000, 2009 and 2012, which is retrieving of typhoon years. Higher values of SL can be explained as the more rainfall leading to more river discharge and higher SST values over the study area. Monthly plot is revealing there is a seasonal variation, which are discussing in the next section.

\subsection{Interseasonal Variations of SL at Different Seasons}

Figure 2 indicates interseasonal variations clearly indicating that, spring is having lower SL and autumn and winter having higher SL. From 1975 to 1987 winter season SL is showing decreasing trend, then have an increasing trend. SL in the spring season is lower than other seasons. An interannual variation of spring season is also revealing increasing trend. Interannual summer season variations also indicating trend same as winter and spring seasons.

\subsection{Annual Variations of SL}

The interannual variations of the Zhejiang coast are depicted in Figure 3. In the $1960 \mathrm{~s}$, Sea level is almost below $0.22 \mathrm{~cm}$. In the 1970s, there is an increasing process and then decrease, however the SL is almost above $0.22 \mathrm{~cm}$. The highest sea level found on 1975. Since 1980s, the sea level of every year is nearly above $0.2 \mathrm{~cm}$, indicating an increasing trend. Previous studies have shown that the large deflection of the Kuroshio can lead to the rise of sea level [28]. Due to the Kuroshio, it carries a large amount of high temperature and high salt water into the East China Sea. It has a great influence on the marine environment in the East China Sea [29] [30].

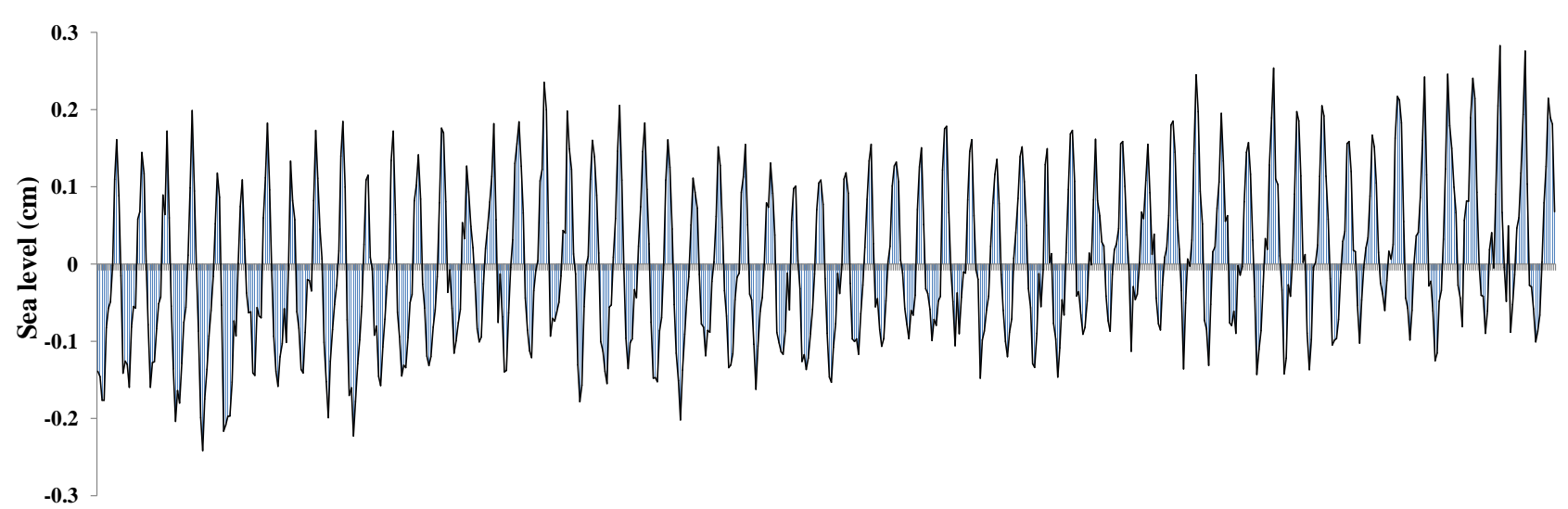

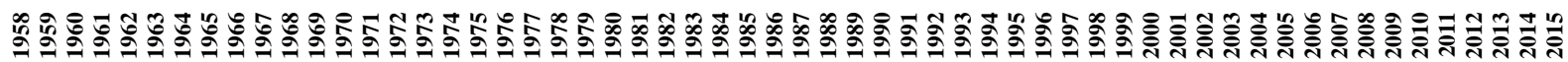
Year

Figure 1. Monthly variation of sea level over Zhejiang coast. 


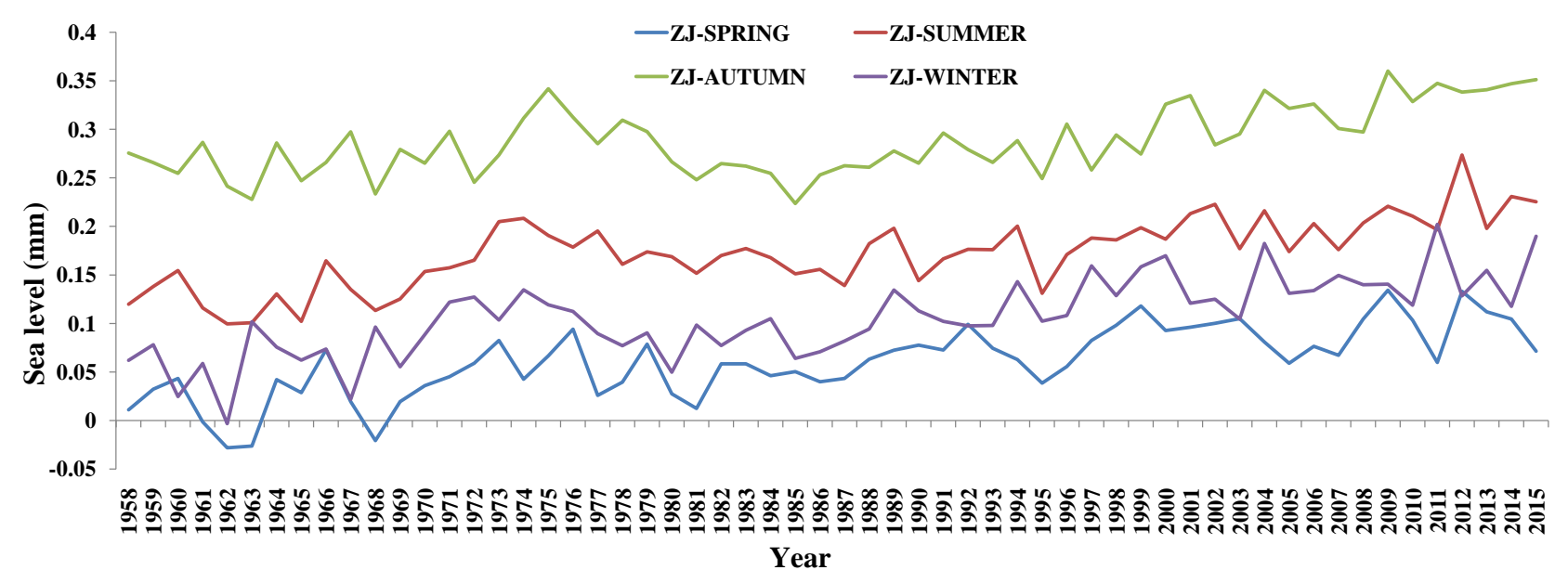

Figure 2. Seasonal variation of sea level over Zhejiang coast.

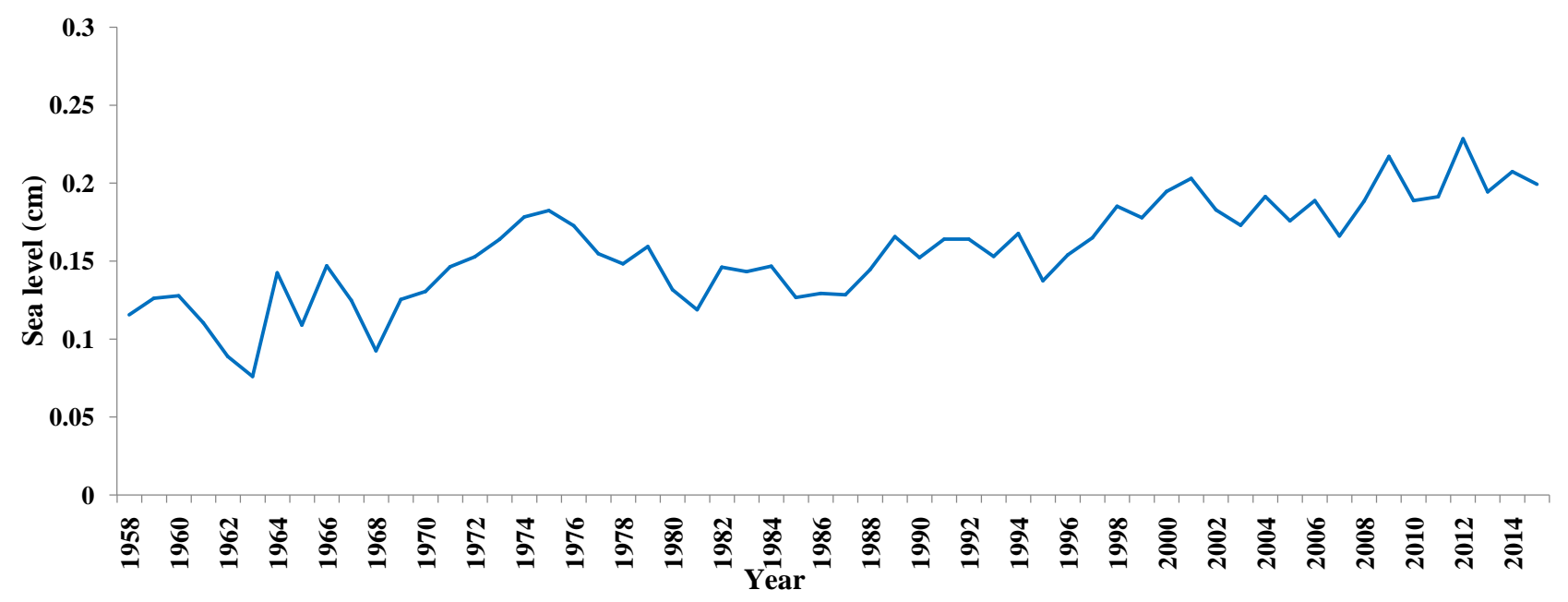

Figure 3. Sea level variation over Zhejiang coast during the study period (1958-2015).

Sea level variation is the appearance of this effect. During El Nino years the sea level decreased. During the El Nino time, most years the sea level is low, it shows that El Nino events have a great influence on the change of sea level in Zhejiang province. During the formation and development of El Nino, Equatorial westerly anomaly, the tropical Pacific warm water from west to East, the East Pacific Ocean warming, sea level rise, while the Western Pacific sea water cooling, so that the sea level dropped.

From Figure 4, annual SL anomalies are indicating clear evidence of increase in SL during the study period. Since 1998, SL showing an increasing trend. The variations of SL at different time scales are given in the next section.

\subsection{Sea Level Variations during the Study Period at Different Time Scales}

The sea level variations during the different scales are given in Figure 5. Plot them use the anomaly data which calculate in the monthly average value subtract 


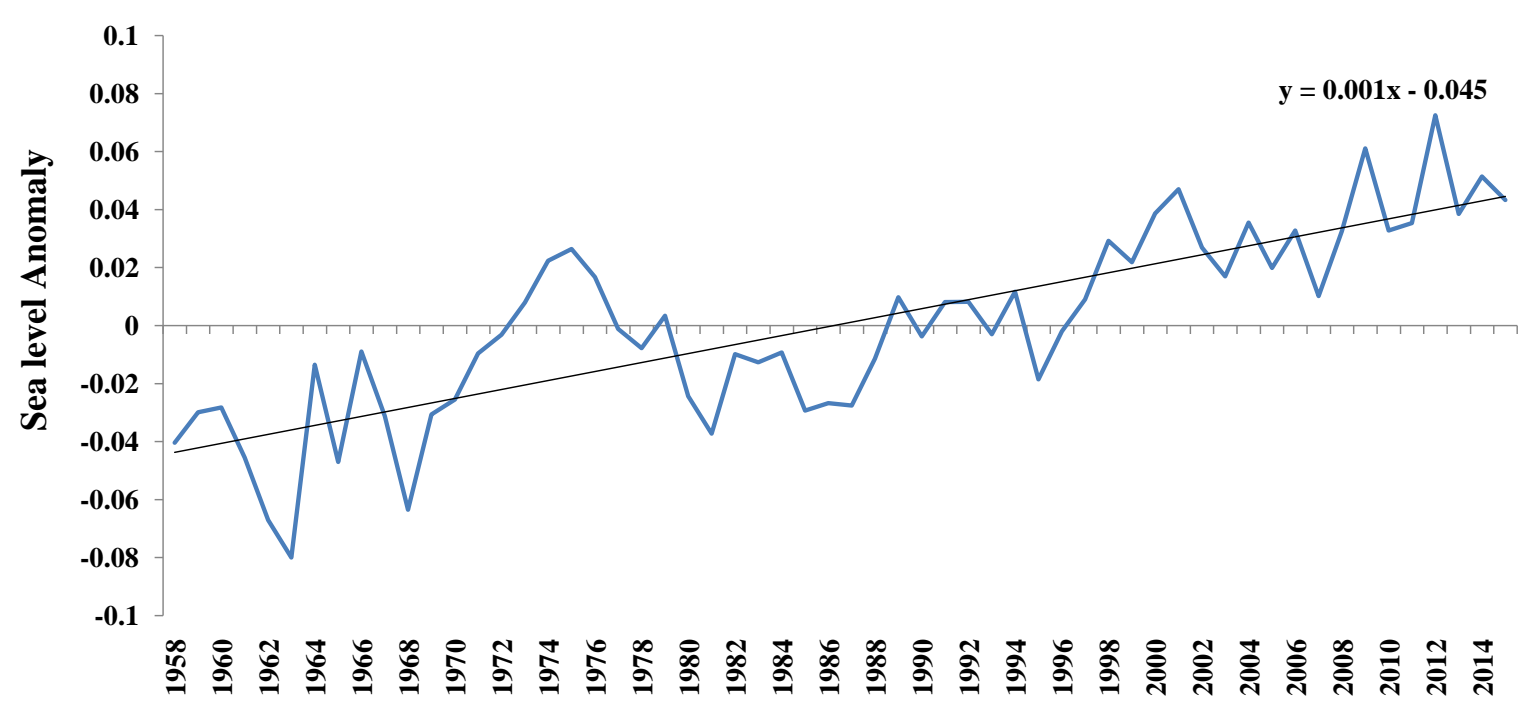

Figure 4. Annual variation of sea level anomalies over Zhejiang coast.

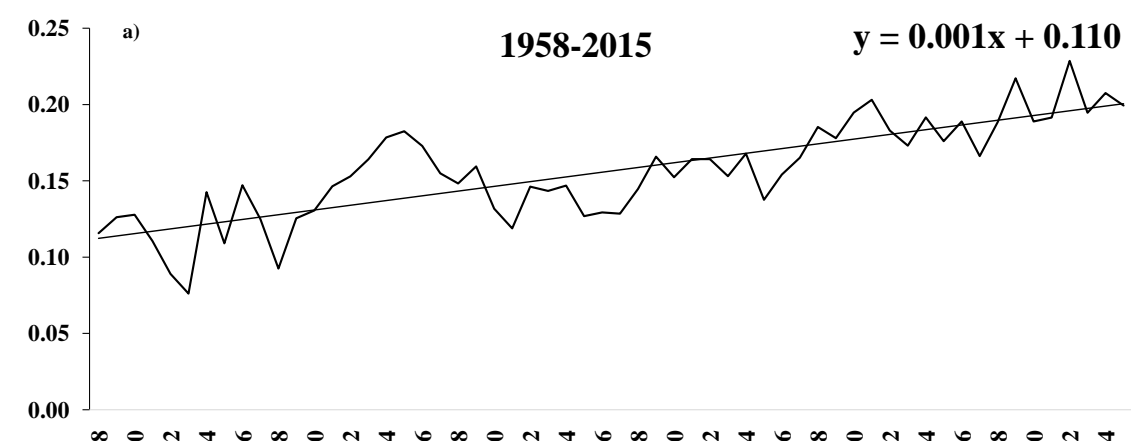

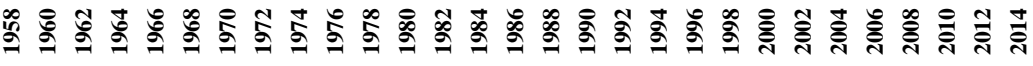

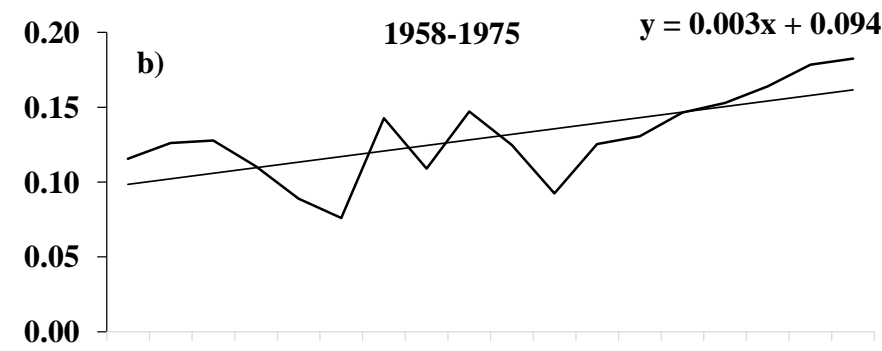

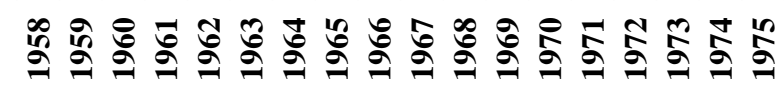

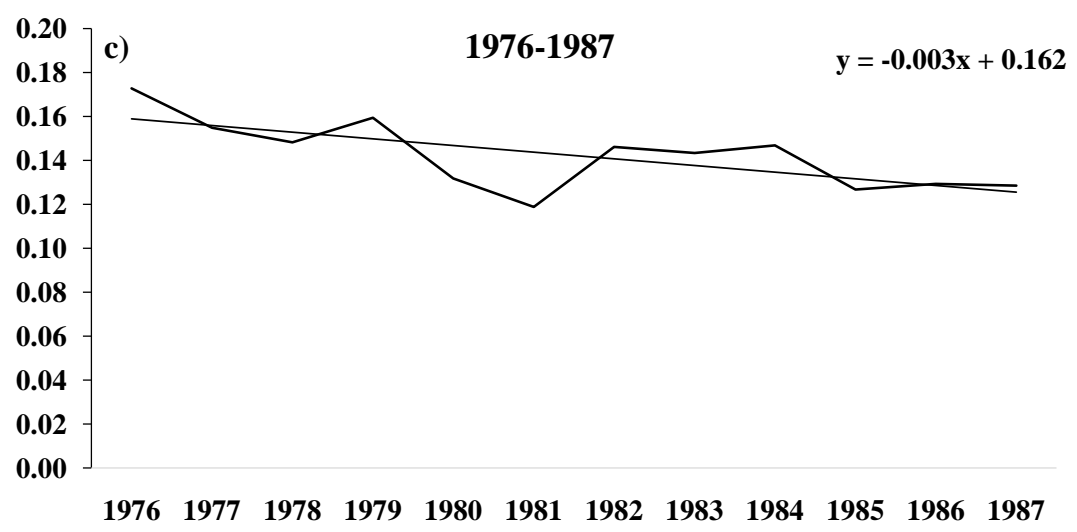




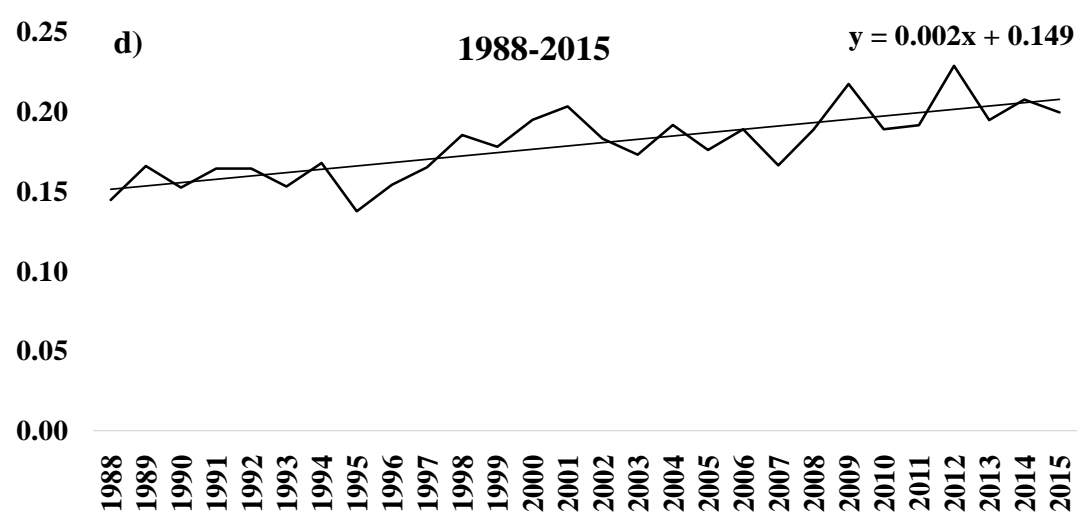

Figure 5. SL variations at different time scales.

the many years monthly average value. Showing that 1958-2015 increasing rate is $0.1715 \mathrm{~cm} / \mathrm{a}, 1958-1975$ is $0.3431 \mathrm{~cm} / \mathrm{a}$, and from 1987 to 2015 is $0.2377 \mathrm{~cm} / \mathrm{a}$. And from 1975 to 1987 is decreasing trend, the change rate is $-0.2635 \mathrm{~cm} / \mathrm{a}$.

\subsection{Spatial Variations of SL during 1993-2012}

Figure 6 shows the geographical distribution of the sea level change trend did by the Maps of Sea Level Anomalies (MSLA). Generally, the whole Zhejiang coast is experiencing a sea level rising with different rates. Figure 6 shows the sea level is decreasing in Taizhou and Wenzhou area from 1993 to 2000. Figure 7 shows most places are positive value, it indicates that the sea level is increasing from 2000 to 2012. One major reason may be that the sea surface temperature is increasing.

\subsection{SL Variations Related to SST}

Temperature to a large extent influence the change of sea level, Changes in sea surface temperature will inevitably lead to the change of sea level. This article uses the SST (HadISST) data used to compare the relation between annual SST and SL over Zhejiang province given in Figure 7 to compare the variations. The Yellow curve in the figure represents the sea surface temperature and the blue curve shows the sea level. By contrast, we find that the sea surface temperature changes in the former then the sea level changes. It indicated that in 1970 the sea surface temperature is the lowest in Zhejiang province. An abrupt drop in Northern Hemisphere sea surface temperature around 1970 [31]. After that SST increasing until 1998 reached the maximum values. During this period of time, the sea level has been increasing as well.

In order to find the relation between SL and SST, a scatter plot has been plotted and presented in Figure 8 during the study period. The correlation coefficients between SL and SST (0.73) depict a significant relation. The significant strong correlation clearly indicates the steric effect of SST on SL.

\section{Discussion}

Global warming leads to expansion of the ocean, polar ice caps and terrigenous Melting glaciers are the main reason of global sea level rise [32]. From the global 


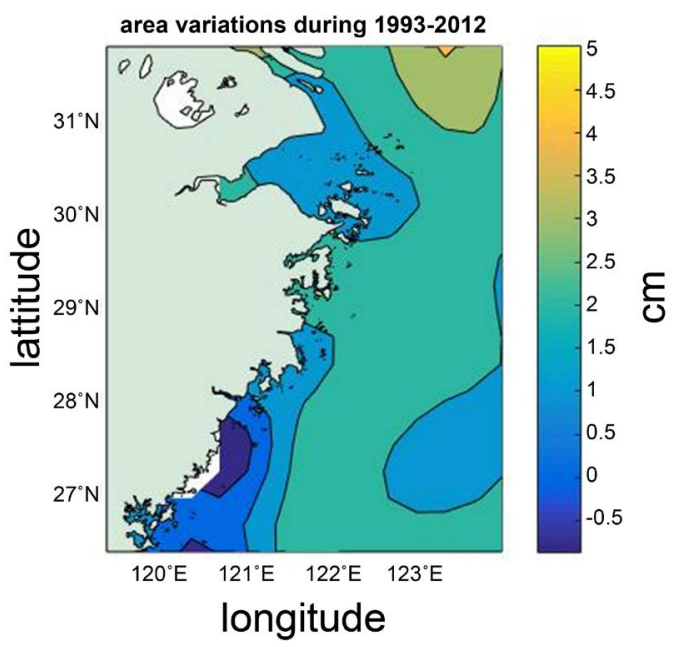

(a)

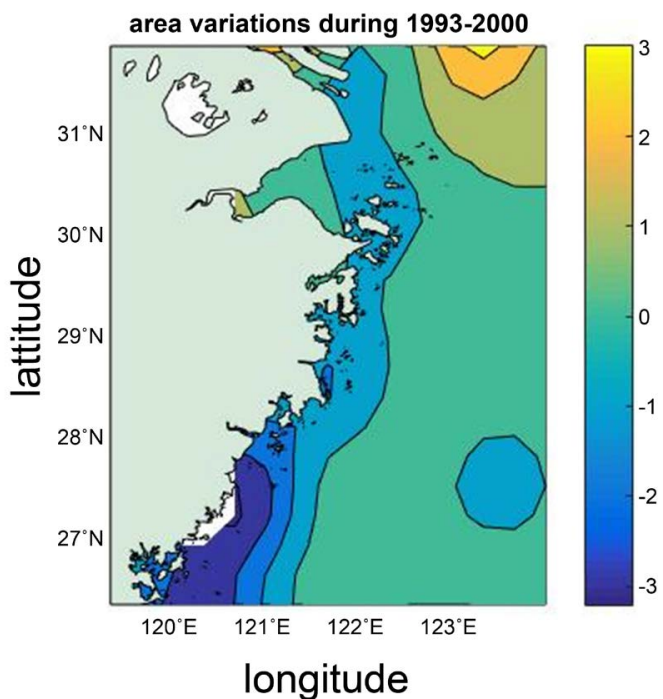

(b)

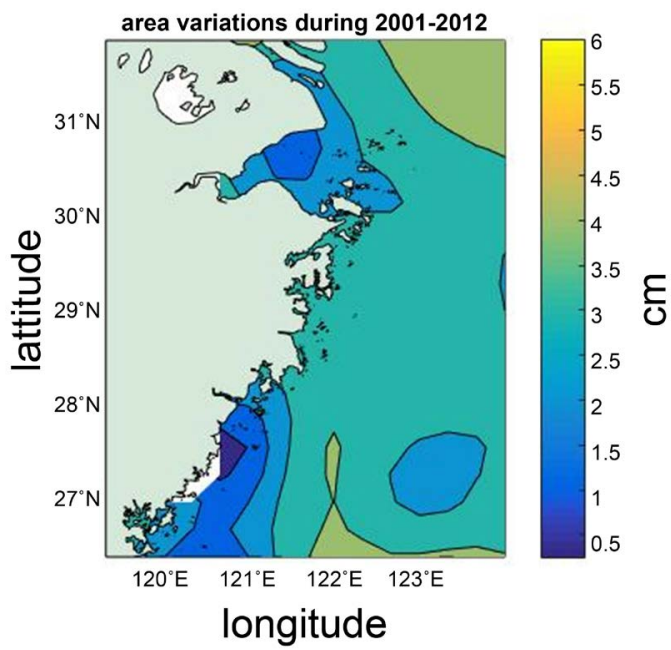

(c)

Figure 6. Spatial variation of Sea levels: (a) during the period 1993-2012, (b) during the period 1993-2000, (c) during the period 2001-2012. 


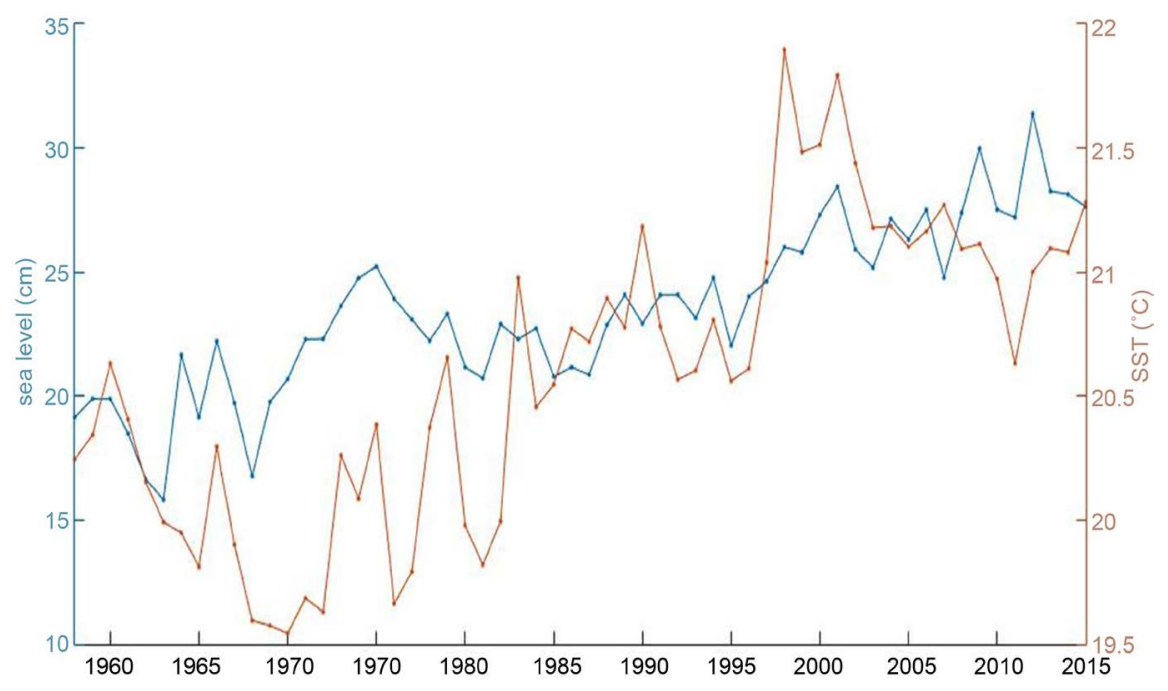

Figure 7. Annual variation of SL and Sea surface temperature (SST). Blue line indicates the sea level and orange line indicates SST.

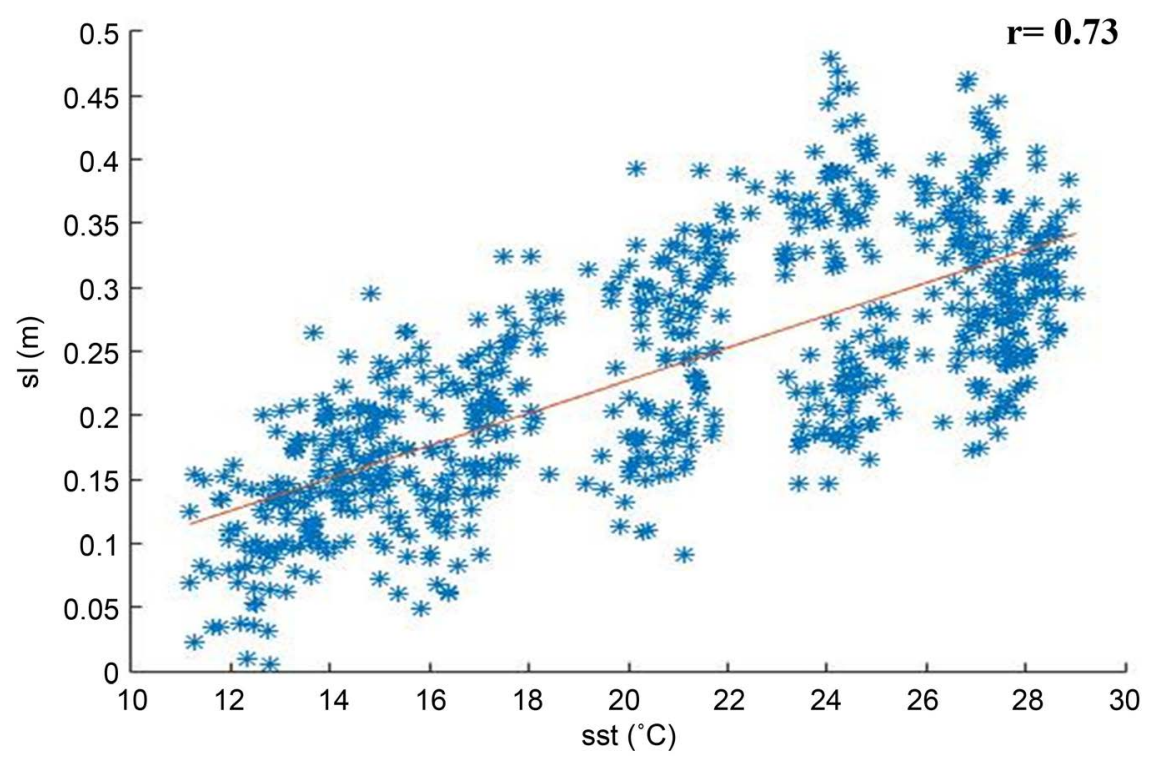

Figure 8. Scatter plot indicates the relation between SL and SST $(r=0.73)$.

sea level rise distribution Sea level changes in the world oceans has obvious regional characteristics [26]. China's coastal areas are located in a relatively high level of sea level rise rate is higher [33].

Regional SL changes in addition to the affected by the global sea level change, also by the local SST, current, wind, temperature, pressure, precipitation and so on hydrologic meteorological elements [34], higher SST and lower pressure, sea level rise [7] [35]. Since 1990, with extreme weather and climate events occur frequently, resulting in the number of abnormal seasonal sea level increase obvious, anomaly values increased [36]. The affection of the East Asian monsoon changes also is the important cause of the change of China's coast and the neighboring seas Marine environmental elements (such as Seawater temperature and salinity, 
sea level, etc.) [26] [37]. The relation between the sea temperature and SL is given in Figure 7 and Figure 8. There is a positive relation can be seen between SST and SL with the correlation of 0.73 . And Figure 7 indicating an increase tend of SST as well as SL during the study period.

\section{Conclusion}

Over the Zhejiang province area, an increasing trend is revealed in SL in monthly, seasonally and interannual variations. SL is increased $0.1715 \mathrm{~cm}$ per year from 1958 to 2015. From 1975 to 1987 is decreased $0.2635 \mathrm{~cm} / \mathrm{a}$. As previous studies indicating that SST in having an impact on SL, we found there is a positive relation between Zhejiang area SST and SL. The correlation coefficient is 0.73 . Local SST, river discharge, sediment present in the water are having sufficient impact on the SL. However, Zhejiang area experience several typhoons and also rainfall, which may also have sufficient effect on SL variations.

\section{Conflicts of Interest}

The authors declare no conflicts of interest regarding the publication of this paper.

\section{References}

[1] Nerem, R.S. and Leuliette, C. (2006) A Present-Day Sea-Level Change: Are Review. Comptes Rendus Geoscience, 338, 1077-1083.

https://doi.org/10.1016/j.crte.2006.09.001

[2] Church, J.A. (2001) Sea Level Rise: History and Consequences. Eos Transactions American Geophysical Union, 82, 376. https://doi.org/10.1029/01EO00232

[3] Church, J., Gregory, J.M., Huybrechts, P., Kuhn, M., Lambeck, K., Nhuan, M.T., Qin, D. and Woodworth, P.L. (2001) Changes in Sea Level. In: Houghtonetal, J.T., Ed., Climate Change 2001: The Scientific Basis, Cambridge University Press, Cambridge, 639-693.

[4] Woodworth, P., Gregory, J.M. and Nicholls, R.J. (2004) Long Term Sea Level Changes and Their Impacts. In: Robinson, A.R. and Brink, K., Eds., The Sea, Biological-Physical Interactions in the Sea, Vol. 12, Harvard University Press, Cambridge, 717-752.

[5] Li, C.Y., Sun, S.Q. and Mu, M.Q. (2001) Origin of the TBO-Interaction between Anomalous East-Asian Winter Monsoon and ENSO Cycle. Advances in Atmospheric Sciences, 18, 555-566. https://doi.org/10.1007/s00376-001-0044-y

[6] Wang, H., Liu, K.X., Zhang, J.L., et al. (2013) The Sea Level Change of Sansha Seas. Acta Oceanologica Sinica, 35, 11-17. (In Chinese)

[7] The State Oceanic Administration (2013) In 2012 China Sea Level Communique.

[8] Ma, J., Zhou, Y.H., Liao, D.C., et al. (2007) Global Sea Level Change from 1992 to 2007. Annals of Shanghai Astronomical Observatory, 1, 37-41.

[9] Zheng, W.Z. and Zhao, X.C. (1985) China's Coatime. Acta Oceanologica Sinica, 7, 276-279.

[10] Zheng, W.Z., Yu, J.Y. and Niu, B. (1992) Sea Level Research in China. Marine Science Bulletin, 11, 68-72. 
[11] Chen, Z.Y., Huang, Y.H., Zhou, T.H., Tang, E.X., Yu, Y.F. and Tian, H. (1991) A Preliminary Study on Mean Sea Level of the Changjiang River Estuary. Oceanologia et Limnologia Sinica, 22, 315-320.

[12] Zhou, T.H. and Chen, Z.Y. (1992) China's Coastal Sea Level Change Trend of Research in Recent Decades. Acta Oceanologica Sinica, 14, 1-8.

[13] Yu, D.Y. (1986) Preliminary Analysis of China Coastal Sea Change Trend during the Past 20 Years. The Chinese Academy of Geological Sciences 562 Comprehensive Brigade Collected Papers.

[14] Fang, Q.Y. and Shi, R.H. (1985) Over the Past Century the World Sea Level Changes. Marine Science Bulletin, 4, 1-5.

[15] Chen, X.Q. (1990) Sea-Level Changes from 1922 to 1987 in the Changjiang River Mouth and Its Significance. Acta Geographica Sinica, 45, 387-398.

[16] Department of Geological of the Chinese Academy of Sciences (1994) The Influence and Strategy of Sea Level Rise to Delta Region in China. Science Press, Beijing.

[17] Cazenave, A., Dominh, K., Gennero, M.C. and Ferret, B. (1998) Global Mean Sea Level Changes Observed by Topex-Poseidon Altimetry and ERS-1. Physics and Chemistry of the Earth, 23, 1069-1075. https://doi.org/10.1016/S0079-1946(98)00146-3

[18] Repert, J.P., Donguy, J.R., Elden, G., et al. (1985) Relations between Sea Level, Thermocline Depth, Heat Content, and Dynamic Height in the Tropical Pacific Ocean. Journal of Geophysical Research, 90, 11719-11725. https://doi.org/10.1029/JC090iC06p11719

[19] White, W.B. and Tai, C.K. (1995) Inferring Interannual Changes in Global Upper Ocean Heat Storage from TOPEX Altimetry. Journal of Geophysical Research, 90, 24943-24954.

[20] Chambers, D.P., Tapley, B.D. and Stewart, R.H. (1997) Long-Period Ocean Heat Storage Rates and Basin-Scale Heat Fluxes from TOPEX. Journal of Geophysical Research, 102, 10525-10533. https://doi.org/10.1029/96JC03644

[21] Chen, J.L., Shum, C.K., Wilson, C.R., et al. (2000) Seasonal Sea Level Change from TOPEX/Poseidon Observation and Thermal Contribution. Journal of Geodesy, 73, 638-647. https://doi.org/10.1007/s001900050002

[22] Cabanes, C., Cazenave, A. and Le Provost, C. (2001) Sea Level Rise during Past 40 Years Determined from Satellite and in Situ Observations. Science, 294, 840-842. https://doi.org/10.1126/science.1063556

[23] Leuliette, E.W. and Wahr, J.M. (1999) Coupled Pattern Analysis of Sea Surface Temperature and TOPEX/POSEIDON Sea Surface Height. Journal of Physical Oceanography, 29, 599-611. https://doi.org/10.1175/1520-0485(1999)029<0599:CPAOSS >2.0.CO;2

[24] Nerem, R.S. and Mitchum, G.T. (2001) Sea Level Change. In: Fu, L.-L. and Cazenave, A., Eds., Satellite Altimetry and Earth Sciences. A Handbook of Techniques and Applications, Academic Press, Cambridge, 329-347. https://doi.org/10.1016/S0074-6142(01)80153-4

[25] Nerem, R.S. and Mitchum, G.T. (2001) Observations of Sea Level Change from Satellite Altimetry. In: Douglas, B.C., Kearney, M.S. and Leatherman, S.P., Eds., Sea Level Rise: History and Consequences, Academic Press, Cambridge, 121-159. https://doi.org/10.1016/S0074-6142(01)80009-7

[26] IPCC (2007) Climate Change 2007: The Physical Science Basis, Summary for Policy makers. Contribution of Working Group I to the Fourth Assessment Report of the Intergovernmental Panel on Climate Change, Intergovernmental Panel on Climate Change. 
[27] Chen, H.L. and Rizzoli, P.M. (2013) Sea Level Rising Trends in the South China Sea over 1993-2011. APAC2013, Bali, 24-26 September 2013, 979-983.

[28] Pu, Y.X. (1988) The Monthly Average Seasonal Changes in the Sea Level of China Coast. Acta Oceanologica Sinica, 10, 292-302.

[29] Pu, Y.X. and Xu, X.Y. (1986) The Black Tide of the East China Sea during 1972-1983. Acta Oceanologica Sinica, 8, 14-20.

[30] Li, K.P., Fang, X.Y., Liu, L.H., et al. (1993) Response of the Sea Level Changes to Variabilities of the Kuroshio. Marine Science Progress, No. 4, 30-37.

[31] Thompson, D.W.J., Wallace, J.M., Kennedy, J.J., et al. (2010) An Abrupt Drop in Northern Hemisphere Sea Surface Temperature around 1970. Nature, 467, 444. https://doi.org/10.1038/nature09394

[32] Yu, Y.F. (2004) Advance of Researches on the Variations of Mean-Sea-Level (MSL) in the Coastal Water of China. Periodical of Ocean University of China (Natural Science Edition), 34, 713-719.

[33] Zuo, J.C., Yu, Y.F. and Chen, Z.Y. (1994) The Analysis of Factor along China Coast. Advance in Earth Sciences, 9, 48-53.

[34] The State Oceanic Administration (2012) In 2011 China Sea Level Communique.

[35] Zhang, J.L., Chen, M.C., Chen, M.X., et al. (2009) Characteristics of SST Variation/Change in the Coastal Region of the East China Sea. Proceeding of the Nineteen International Offshore and Polar Engineering Conference, Osaka, 21-26 July 2009, 483-489.

[36] Zuo, J.C., Du, L., Chen, M.X., et al. (2013) Sea Level Change and Its Impact and Application under the Background of Climate Change. Science Press, Beijing.

[37] Cai, R.S., et al. (2010) The Effects of Climate Change on China's Coastal Ecosystem. Ocean Press, Beijing. 